\title{
Genetic analysis of clinical mastitis data for Holstein cattle in the Czech Republic
}

\author{
L. Zavadilová ${ }^{1}$, M. Štípková ${ }^{1}$, N. Šebková ${ }^{2}$, and A. Svitáková ${ }^{1}$ \\ ${ }^{1}$ Institute of Animal Science, v.v.i, Prague, Czech Republic \\ ${ }^{2}$ Czech University of Life Science Prague, Faculty of Agrobiology Food and Resources, Department of \\ Husbandry and Ethology of Animals, Prague, Czech Republic \\ Correspondence to: L. Zavadilová (lida.zavadilova@seznam.cz)
}

Received: 6 September 2014 - Accepted: 17 April 2015 - Published: 21 May 2015

\begin{abstract}
Cases of mastitis were recorded from 22812 lactations of 10294 cows on seven farms in the Czech Republic from 2000 to 2012. The per cow number of clinical mastitis (CM) cases per lactation (CM1), number of days of CM per lactation (CM2), and CM considered as an all-or-none trait (CM3) with values of 0 (no CM case) or 1 (at least $1 \mathrm{CM}$ case) were analyzed with linear animal models. Bivariate linear animal models were used for estimation of genetic correlations between CM traits and average lactation somatic cell score (SCS305), average 305-day milk (MY305), fat (FY305) and protein (PY305) yield, and interval between calving and first insemination (INT) and days open (DO). Factors included in the model of choice were parity, herd effect, year of calving, calving season, permanent environmental effect of the cow, and additive genetic effect of the cow. Estimated heritabilities for CM traits were in the range of 0.09 to 0.10 . Genetic correlations of SCS305 with CM traits 1,2 , and 3 were $0.22 \pm 0.062,0.23 \pm 0.064$, and $0.29 \pm 0.086$, respectively; those of MY305 with the three CM traits were $0.80 \pm 0.037,0.79 \pm 0.040$, and $0.83 \pm 0.038$, respectively; those of INT with the three CM traits were $0.19 \pm 0.087,0.17 \pm 0.089$, and $0.26 \pm 0.091$, respectively; and those of DO with the three CM traits were $0.28 \pm 0.089,0.22 \pm 0.091$, and $0.27 \pm 0.091$, respectively. Knowledge of genetic parameters of mastitis incidence and assessment of the economic importance of the disease is necessary to design breeding programs to improve udder health.
\end{abstract}

\section{Introduction}

Mastitis is the most common and costly disease in European dairy cattle populations (Halasa et al., 2007; Wolfová et al., 2006). Improving animal health is becoming increasingly important worldwide. Accordingly, many genetic selection programs are focusing on improving disease resistance and functionally important traits (Zwald et al., 2006). The most effective method would be to use direct measures of health or disease as selection criteria, but to do so such traits would have to be included in recording, evaluation and selection schemes. Unfortunately, routine recording of clinical mastitis is not implemented in many countries, although it has been well established in the Nordic countries for more than 40 years (Carlén, 2008). Direct scoring and recording of udder health traits is limited in the Czech Republic, and conse- quently breeding values for somatic cell score, estimated by animal model with random regression, have been the primary indicator trait for udder health. Breeding values have also been calculated for linear type traits including udder conformation score since 1999. Registration of every clinical mastitis (CM) occurrence has been obligatory on all dairy farms since 1997 but mainly through recording each use of relevant pharmaceuticals. Each antibiotic treatment and identification of each affected quarter must be recorded on farm. However, resultant records are not transferred to a central database, and their availability is limited.

Wolfová et al. (2006) computed an estimated economic weight for CM. An association between a potential marker for mastitis, CGIL4, and breeding value for somatic cell count (SCC) was reported by Čítek et al. (2011). Wang et al. (2014) suggest that the CD46 gene likely plays a criti- 
cal role in the risk of mastitis caused by Streptococcus in dairy cows via an alternative splicing mechanism caused by a functional mutation in intron 8. In a genome-wide association study, Abdel-Shafy et al. (2014) identified 10 singlenucleotide polymorphisms (SNPs) representing 6 genomic regions that were associated with daughters' yield deviation for somatic cell score in German Holstein bulls. All tested SNPs were significant in cows. Seven of them, located on Bos taurus autosomes (BTA) 6, 13, and 19, had the same directional effect as those previously reported in the bull population. The most significant associations were detected on BTA6 and BTA19, accounting for $1.8 \%$ of the total genetic variance.

Knowledge of genetic parameters for mastitis incidence and assessment of the economic importance of the disease are necessary in developing breeding programs to improve udder health. The objective of the present study was to estimate genetic parameters for clinical mastitis traits and genetic relationships of such traits with other production and functional traits recorded on Czech dairy farms.

\section{Material and methods}

\subsection{Animals and trait definitions}

Data on mastitis incidence were collected from seven Holstein herds between 2000 and 2012. The numbers of years during which each herd was recorded are shown in Table 1. The farms were not randomly chosen from the nationally recorded population but rather were those willing to participate in the study. They varied in size and were from distinct regions but all used management, feeding, and housing systems commonly applied to dairy herds in the Czech Republic. Straw was used for bedding on all farms, and all cows were fed a balanced total mixed ration (TMR) and milked twice a day.

Records collected on farms included cow identification, date at the beginning of each CM treatment, date at the end of each CM incident (i.e., the last day that milk from a treated cow was discarded), and identification of treated quarters. Farmer detection of CM was accomplished by visual examination of the udder or milk. However, a mastitis case was recorded only if it was treated with antibiotics prescribed by a veterinarian. Thus, $\mathrm{CM}$ was defined as a veterinary-treated udder disease.

Traits of interest for each cow were the number of CM cases per lactation (CM1), the number of days of CM per lactation (CM2), and CM considered as an all-or-none trait (CM3) with values of 0 (no CM case) or 1 (at least $1 \mathrm{CM}$ case) per lactation. A new case of CM for the same cow was indicated when the period between the end of the previous case and the beginning of the next occurrence was at least 5 days. The distribution of cows classified according to the number of CM cases per lactation is shown in Table 1.
Additional analyzed traits included production traits (305day milk, MY305; fat, FY305; and protein yield, PY305), reproductive traits (time between calving and first insemination, INT; days open, DO), and udder health (average lactation somatic cell count, SCC). Somatic cell count was not analyzed directly but was first transformed to somatic cell score (SCS305) according to the following formula:

$\operatorname{SCS} 305=\log _{2}\left(\frac{\mathrm{SCC}}{100000}\right)+3$.

Data required for genetic evaluation of CM (birth date, calving data, parity, length of lactation, culling data, cumulative milk yield per lactation, average lactation somatic cell count, etc.) together with the pedigree file were made available from the national database for progeny testing. Only cows that started their lactation after the initiation of data collection and that had a lactation length of at least 240 days and a lactation yield of at least $2000 \mathrm{~kg}$ of milk were included in the analysis. For analysis of fertility traits, only records between 21 and 280 days for INT and between 42 and 400 days for DO were used in the analysis. For cows without a subsequent calving, INT and DO were penalized by adding 21 days. If INT or DO length exceeded the maximum value, then the value of INT or DO was set to the maximum value.

The numbers of cows and lactations in the analyzed data set after editing are shown in Table 2 . Cows were progeny of 1424 sires, and the number of daughters per sire ranged from 1 to 227 , with a median of 6 .

\subsection{Statistical methods}

The following linear animal model was used to estimate genetic parameters for CM traits, SCS, production, and reproduction traits:

$$
\begin{aligned}
& y_{i j k l m n}=\text { parity }_{1}+\text { herd }_{j}+\text { year }_{k}+\operatorname{season}_{l}+\text { pe }_{m} \\
& +a_{n}+e_{i j k l m n},
\end{aligned}
$$

where $y_{i j k l m n}$ is the number of $\mathrm{CM}$ cases, the number of days of CM per lactation, or CM considered as an all-ornone trait with values of 0 (no CM case) or 1 (at least 1 CM case); SCS305, MY305, FY305, PY305, INT, and DO are variables; parity ${ }_{1}$ is the effect of parity class $i$ (4 levels: first, second, third, fourth, and higher parity); herd ${ }_{j}$ is the effect of herd $j$ (7 levels); year $_{k}$ is the effect of calving year $k$ (12 levels); $\operatorname{season}_{l}$ is the effect of calving season (4 levels: January-March, April-June, July-September, OctoberDecember); $\mathrm{pe}_{m}$ is the random permanent environmental effect on cow traits across $m$ sequential lactations; $a_{n}$ is the random additive genetic effect of cow $n$; and $e_{i j k l m n}$ is the random residual effect. The pedigree file contained 25359 records. Data were analyzed using the DMU package (Madsen and Jensen, 2010). Genetic correlations between traits were estimated using bivariate models. 
Table 1. Characteristics of seven herds contributing data on mastitis occurrence and economically important production traits.

\begin{tabular}{llrrrrr}
\hline Herd & $\begin{array}{l}\text { Data collection } \\
\text { period }\end{array}$ & $\begin{array}{r}\text { Average herd } \\
\text { size }^{1}(\text { cows })\end{array}$ & $\begin{array}{r}\text { Cows } \\
(n)\end{array}$ & $\begin{array}{r}\text { Total } \\
\text { lactations }(n)\end{array}$ & $\begin{array}{r}\text { Mastitis } \\
\text { cases }(n)\end{array}$ & $\begin{array}{r}\text { Lactations with } \\
\text { mastitis }(\%)^{2}\end{array}$ \\
\hline 1 & $2000-2012$ & 900 & 4006 & 9038 & 6072 & 34.3 \\
2 & $2002-2012$ & 500 & 1665 & 4032 & 1819 & 30.0 \\
3 & $2000-2012$ & 150 & 556 & 1184 & 1282 & 46.7 \\
4 & $2004-2012$ & 150 & 397 & 843 & 506 & 37.8 \\
5 & $2000-2012$ & 200 & 760 & 1708 & 1109 & 38.4 \\
6 & $2000-2012$ & 150 & 619 & 1428 & 1752 & 48.2 \\
7 & $2000-2012$ & 500 & 2291 & 4579 & 5066 & 51.4 \\
\hline Total & & 10294 & 22812 & 17606 & 38.8 \\
\hline
\end{tabular}

${ }^{1}$ Approximate average number of cows per herd per year.

$2100 \%$ total lactations.

Table 2. Descriptive statistics of CM traits, SCS, milk production, and fertility.

\begin{tabular}{llrrrrr}
\hline Trait & Unit & Observations & Mean & SD & Min & Max \\
\hline CM1 $^{1}$ & no./lactation & 8863 & 1.99 & 1.62 & 1 & 18 \\
CM2 & days & 8843 & 11.52 & 12.14 & 1 & 163 \\
CM3 & no. & 22812 & 0.39 & 0.49 & 0 & 1 \\
MY305 & kg & 22501 & 9202 & 2096 & 856 & 16990 \\
FY305 & kg & 22490 & 348.1 & 77.34 & 73 & 737 \\
PY305 & kg & 22490 & 299.9 & 63.80 & 66 & 530 \\
SCS305 & & 15209 & 3.64 & 1.13 & 0.88 & 6.60 \\
INT & days & 21379 & 89.00 & 35.80 & 21 & 280 \\
DO & days & 19343 & 137.55 & 71.62 & 42 & 400 \\
\hline
\end{tabular}

${ }^{1}$ Only for lactations with $\mathrm{CM}$ cases.

CM1: number of CM cases per lactation; $\mathrm{CM} 2$ : the number of days in CM per lactation; CM3: CM considered as an all-or-none trait with values of 0 (no CM case) and 1 (at least $1 \mathrm{CM}$ case); MY305: 305-day milk yield; FY305: fat yield; PY305: protein yield; SCS305: average SCS; INT: interval between calving and the first insemination; DO: days open.

\section{Results and discussion}

\section{Genetic parameters}

Variance components and their standard errors and estimates of genetic parameters for the three CM traits are shown in Table 3. Additive genetic variances differed significantly from zero for all of the CM traits. Permanent environmental effects of the cow were approximately two-thirds as large as the additive genetic variances for CM1 and CM3, whereas for CM2, the permanent environmental cow effect was threequarters as large as the additive genetic variance. Residual variance accounted for $86 \%$ of total variance for CM3 and $83 \%$ for CM1 and CM2. Heritability estimates were 0.10 for CM1 and CM2 and 0.09 for CM3 (mastitis considered as an all-or-none trait). These estimates are in close agreement with Wolf et al. (2010), who reported heritability for the number of mastitis cases per lactation in the range of 0.11 to 0.13. Pérez-Cabal and Charfeddine (2013) reported heritability estimates of 0.04 and 0.05 for CM defined as an allor-none trait and for number of cases of mastitis per lactation, values somewhat lower than current results. For CM defined as number of cases per lactation, Pérez-Cabal et al. (2009) and Vazquez et al. (2009) reported heritabilities around 0.10. Heritability estimates for mastitis defined as an all-or-none trait have generally been low, especially from linear model analyses. Heringstad et al. (2000), for example, reported values from 0.02 to 0.03 and Carlén et al. (2004) a value of 0.03 for CM defined as a binary trait during first lactation and 0.01 for later lactations. When the binary nature of CM was taken into account when fitting threshold models, heritability estimates ranging from 0.06 to 0.12 were reported by Heringstad et al. (2003), Zwald et al. (2006), Negussie et al. (2008), and Pérez-Cabal et al. (2009). Thus, the magnitude of heritability estimates can depend upon trait definition. Defining CM as a binary trait can lead to less reliable estimation of susceptibility to CM, because there is no distinction among cows with 1 versus multiple CM cases. Variation among cows can be accounted for by including the number of CM cases in the evaluation and considering CM incidence in different parities as a repeatable trait.

Our heritability estimate for SCS305 of 0.23 was higher than estimates of Carlén et al. (2004) and Buch et al. (2011). 
Table 3. Variance components and their standard errors (in parentheses) estimated for the number of clinical mastitis (CM) cases per lactation, the number of days of CM per lactation, and CM considered as an all-or-none trait with values of 0 (no CM case) and 1 (at least $1 \mathrm{CM}$ case).

\begin{tabular}{llll}
\hline & CM1 & CM2 & CM3 \\
\hline Variance estimate & & & \\
Additive genetic & $0.188(0.020)$ & $8.119(0.912)$ & $0.019(0.002)$ \\
Permanent environment & $0.131(0.020)$ & $6.350(0.913)$ & $0.012(0.002)$ \\
Residual & $1.492(0.018)$ & $68.235(0.814)$ & $0.193(0.002)$ \\
Heritability & 0.10 & 0.10 & 0.09 \\
Repeatability & 0.17 & 0.17 & 0.14 \\
& MY305 & FY305 & PY305 \\
Heritability & 0.15 & 0.11 & 0.12 \\
Heritability & SCS305 & INT & DO \\
\hline
\end{tabular}

CM1: number of $\mathrm{CM}$ cases per lactation; $\mathrm{CM} 2$ : the number of days in $\mathrm{CM}$ per lactation; $\mathrm{CM} 3$ : $\mathrm{CM}$ considered as an all-or-none trait with values of 0 (no CM case) and 1 (at least $1 \mathrm{CM}$ case); MY305: 305-day milk yield; FY305: fat yield, PY305: protein yield: INT: interval between calving and first insemination; DO: days open; SCS305: average SCS. All variances are significant at $P<0.001$

Our estimated heritability for MY305 of 0.15 is lower than 0.23 reported by Carlén et al. (2004) and Dědková and Wolf's (2001) estimates of 0.28 to 0.30 , based upon animal model analysis of aggregated 305 day yields during the first three lactations of Czech Holsteins. Our heritabilities for production traits are lower than those commonly reported in the literature. This is probably due to small sample size or file structure.

Estimates of genetic correlations and their standard errors are shown in Table 4. There were large positive genetic correlations among all three $\mathrm{CM}$ traits, ranging from 0.90 to 0.97. Pérez-Cabal and Charfeddine (2013) reported a similarly high additive genetic correlation of 0.93 between CM as an all-or-none trait and CM as number of cases per lactation.

Positive genetic correlations ranging from 0.79 to 0.83 were observed between SCS305 and the three CM traits, in agreement with Carlén et al. (2004) and Odegard et al. (2004). Similarly, Pérez-Cabal and Charfeddine (2013) reported a genetic correlation of 0.85 between SCS305 and $\mathrm{CM}$ as an all-or-none trait and 0.76 between SCS305 and number of $\mathrm{CM}$ cases per lactation. As stated by Heringstad et al. (2006), however, such high correlations do not mean that SCS305 is an ideal indicator of clinical mastitis. SCS is a valid indicator of clinical mastitis because the genetic correlation is high, but the trait is still indirect. The largest response to selection can be expected when the direct trait is used.

Genetic correlations between milk production and CM traits ranged between 0.15 and 0.29 . Unfavorable genetic correlations between CM traits and milk yield as well as the high positive correlations between CM traits and SCS, both observed in our investigation, are in good agreement with correlations between $\mathrm{CM}$ as a binary trait and milk yield $(0.26-0.45)$ or SCS305 (0.58-0.86) reported in the literature (Carlén et al., 2004; Hinrichs et al., 2005; Koivula et al.,
Table 4. Estimates of additive genetic correlations between $\mathrm{CM}$ traits, SCS, and milk production, including their standard errors (in parentheses).

\begin{tabular}{llll}
\hline Trait & CM1 & CM2 & CM3 \\
\hline CM1 & & $0.90(0.016)^{* *}$ & $0.97(0.014)^{* *}$ \\
CM2 & & & $0.93(0.025)^{* *}$ \\
MY305 & $0.23(0.062)^{* *}$ & $0.24(0.063)^{* *}$ & $0.29(0.086)^{* *}$ \\
FY305 & $0.22(0.068)^{*}$ & $0.15(0.071)$ & $0.22(0.072)^{*}$ \\
PY305 & $0.24(0.064)^{*}$ & $0.24(0.067)^{*}$ & $0.26(0.068)^{* *}$ \\
SCS305 & $0.80(0.037)^{* *}$ & $0.79(0.040)^{* *}$ & $0.83(0.038)^{* *}$ \\
INT & $0.12(0.082)$ & $0.09(0.085)$ & $0.20(0.086)^{*}$ \\
DO & $0.30(0.092)^{* *}$ & $0.22(0.091)^{*}$ & $0.22(0.096)^{*}$ \\
\hline
\end{tabular}

$\mathrm{CM} 1$ : number of $\mathrm{CM}$ cases per lactation; $\mathrm{CM} 2$ : the number of days in $\mathrm{CM}$ per lactation; CM3: $\mathrm{CM}$ considered as an all-or-none trait with values of 0 (no $\mathrm{CM}$ case) and 1 (at least 1 CM case); MY305: 305-day milk yield; FY305: fat yield, PY305: protein yield: INT: interval between calving and the first insemination; DO: days open; SCS305: average SCS. ${ }^{* *} P<0.001,{ }^{*} P<0.05$.

2005; Negussie et al., 2006; De Haas et al., 2008; Buch et al., 2011). Additive genetic correlations between $C M$ traits and milk yield in our study are at the lower end of the range of previously cited investigations. Pérez-Cabal and Charfeddine (2013) reported a lower additive genetic correlation of CM as an all-or-none trait to fat yield than we found. In agreement with Pérez-Cabal and Charfeddine (2013), however, we found the genetic correlation of number of $\mathrm{CM}$ cases per lactation to fat yield to be much lower than genetic correlations of number of CM cases with milk yield and protein yield.

As discussed by Wu et al. (2008), the relationship between $\mathrm{CM}$ and milk yield is very complex, and there are reciprocal effects and interactions among the traits. For example, a mastitis episode causes reduced milk production and, at the same time, culling for mastitis occurs with higher frequency in cows with higher milk yield. We are approaching similar conclusions for the Czech Holstein population, but elucida- 
Table 5. Estimates of permanent environmental correlations between CM traits, SCS, and milk production, including their standard errors (in parentheses).

\begin{tabular}{lrrr}
\hline Trait & CM1 & CM2 & CM3 \\
\hline CM1 & & $0.94(0.021)^{* *}$ & $0.75(0.056)^{* *}$ \\
CM2 & & & $0.71(0.062)^{* *}$ \\
MY305 & $0.02(0.075)$ & $-0.05(0.073)$ & $0.15(0.231)$ \\
FY305 & $-0.02(0.069)$ & $-0.02(0.067)$ & $-0.02(0.082)$ \\
PY305 & $-0.05(0.072)$ & $-0.08(0.070)$ & $-0.07(0.084)$ \\
SCS305 & $0.39(0.104)^{* *}$ & $0.28(0.111)^{* *}$ & $0.52(0.111)^{* *}$ \\
INT & $0.29(0.106)^{*}$ & $0.30(0.104)^{*}$ & $0.32(0.121)^{*}$ \\
DO & $0.09(0.098)$ & $0.13(0.095)$ & $0.13(0.096)$ \\
\hline
\end{tabular}

CM1: number of CM cases per lactation; CM2: the number of days in CM per lactation; CM3: CM considered as an all-or-none trait with values of 0 (no CM case) and 1 (at least 1 CM case); MY305: 305-day milk yield; FY305: fat yield; PY305: protein yield; INT: interval between calving and the first insemination; DO: days open; SCS305: average SCS. ${ }^{* *} P<0.001,{ }^{*} P<0.05$.

tion and verification will require further research. Positive genetic correlations between $\mathrm{CM}$ and fertility traits ranged from 0.12 to 0.30 , suggesting that selection for reduced mastitis would result in reduced INT and DO. Pérez-Cabal and Charfeddine (2013) reported genetic correlations of 0.34 between DO and binary CM and 0.40 between DO and number of CM cases. Kadarmideen et al. (2000) reported a genetic correlation of 0.30 between CM as a binary trait and INT. Genetic correlations between CM and fertility traits reported by Pritchard et al. (2013) were of similar magnitude, ranging from 0.27 to 0.33 .

Estimates of permanent environmental correlations and their standard errors are shown in Table 5, while those of residual correlations and standard errors are in Table 6. Positive correlations among CM traits caused by permanent environmental effects of the cow ranged from 0.71 to 0.94 . Permanent environmental correlations between CM traits and SCS305 were positive and statistically significant ( 0.28 to 0.52 ), whereas permanent environmental correlations between $\mathrm{CM}$ traits and production were mostly negative ( -0.05 to 0.15$)$ or near zero. Among fertility traits, INT showed higher permanent environmental correlations $(0.27$ $0.32)$ than DO (0.09-0.13). Again, the highest residual correlations occurred among $\mathrm{CM}$ traits and between $\mathrm{CM}$ traits and SCS305. Cows with a high residual for any one CM trait tend to have high residuals for the others as well.

\section{Conclusions}

Our heritability estimates for number of $\mathrm{CM}$ cases per lactation, number of days in $\mathrm{CM}$ per lactation, and $\mathrm{CM}$ considered as an all-or-none trait were all about 0.10 , and therefore these traits can be expected to respond to selection. We also found large positive genetic correlations among CM traits and confirmed their strong genetic relationship with somatic cell scores. Therefore we conclude that one of these traits
Table 6. Estimates of residual correlations between CM traits, SCS, and milk production, including their standard errors (in parentheses).

\begin{tabular}{lrrr}
\hline Trait & CM1 & CM2 & CM3 \\
\hline CM1 & & $0.84(0.002)^{* *}$ & $0.64(0.005)^{* *}$ \\
CM2 & & & $0.54(0.006)^{* *}$ \\
MY305 & $-0.12(0.008)^{* *}$ & $-0.10(0.009)^{* *}$ & $-0.15(0.008)^{* *}$ \\
FY305 & $-0.11(0.009)^{* *}$ & $-0.09(0.009)^{* *}$ & $-0.11(0.009)^{* *}$ \\
PY305 & $-0.09(0.009)^{* *}$ & $-0.07(0.009)^{* *}$ & $-0.09(0.009)^{* *}$ \\
SCS305 & $0.31(0.008)^{* *}$ & $0.27(0.010)^{* *}$ & $0.26(0.017)^{* *}$ \\
INT & $0.03(0.009)^{*}$ & $0.01(0.009)$ & $0.02(0.009)^{*}$ \\
DO & $0.06(0.009)^{* *}$ & $0.04(0.009)^{* *}$ & $0.04(0.009)^{* *}$ \\
\hline
\end{tabular}

$\mathrm{CM} 1$ : number of $\mathrm{CM}$ cases per lactation; $\mathrm{CM} 2$ : the number of days in $\mathrm{CM}$ per lactation; CM3: CM considered as an all-or-none trait with values of 0 (no CM case) and 1 (at least CM case); MY305: 305-day milk yield; FY305: fat yield; PY305: protein yield: INT: interval between calving and the first insemination; DO: days open; SCS305: average SCS. ** $P<0.001, * P<0.05$

could be used for genetic evaluation of clinical mastitis in Czech Holstein cattle, alone or together with somatic cell score in a bivariate model. This would require development of a recording and data management system.

Acknowledgements. We thank W. D. Hohenboken (Corvallis, OR) for editing the English of the paper and for helpful comments. Thanks are due to Jaroslava Šefrová and Michaela Krejčová, both of Prague Uhříněves (Czech Republic), for collecting data on CM on farms, as well as to the Czech-Moravian Breeder's Corporation (Prague, Czech Republic) for making data on milk performance and SCC available. The access to computing and storage facilities owned by parties and projects contributing to the National Grid Infrastructure MetaCentrum, provided under the program "Projects of Large Infrastructure for Research, Development, and Innovations" (LM2010005), is highly acknowledged. The research was supported through project MZE 0002701404 of the Ministry for Agriculture of the Czech Republic (Prague, Czech Republic).

Edited by: A.-E. Freifrau von Tiele-Winckler

Reviewed by: two anonymous referees

\section{References}

Abdel-Shafy, H., Bortfeldt, R. H., Reissmann, M., and Brockmann, G. A.: Short communication: Validation of somatic cell scoreassociated loci identified in a genome-wide association study in German Holstein cattle, J. Dairy Sci., 97, 2481-2486, 2014.

Buch, L. H., Sorensen, M. K., Lassen, J., Berg, P., Jakobsen, J. H., Johansson, K., and Sorensen, A. C.: Udder health and female fertility traits are favourably correlated and support each other in multi-trait evaluations, J. Anim. Breed. Genet., 128, 174-182, 2011.

Carlén, E.: Genetic evaluation of clinical mastitis in dairy cattle. Doctoral thesis Swedish University of Agricultural Sciences (SLU), Sweden, http://urn.kb.se/resolve?urn=urn:nbn:se: slu:epsilon-2543 (last access: 27 September 2013), 2008.

Carlén, E., Strandberg, E., and Roth, A.: Genetic parameters for clinical mastitis, somatic cell score, and production in the first 
three lactations of Swedish Holstein cows, J. Dairy Sci., 87, 3062-3070, 2004.

Čítek, J., Řehout, V., Hanusová, L., Míková, A., and Jašková, I.: Polymorphisms in CGILA, breeding value for somatic cell count and resistance to mastitis, Czech J. Anim. Sci., 56, 301-304, 2011.

Dědková, L. and Wolf, J.: Estimation of genetic parameters for milk production traits in Czech dairy cattle populations, Czech J. Anim. Sci., 46, 292-301, 2001.

De Haas, Y., Ouweltjes, W., ten Napel, J., Windig, J. J., and de Jong, G.: Alternative somatic cell count traits as mastitis indicators for genetic selection, J. Dairy Sci., 91, 2501-2511, 2008.

Halasa, T., Huijps, J., Osteras, O., and Hogeveen, H.: Economic effects of bovine mastitis \& mastitis management: A review, Vet. Q., 29, 18-31, 2007.

Heringstad, B., Klemetsdal, G., and Ruane, J.: Selection for mastitis resistance in dairy cattle - A review with focus on the situation in the Nordic countries, Livest. Prod. Sci., 64, 95-106, 2000.

Heringstad, B., Rekaya, R., Gianola, D., Klemetsdal, G., and Weigel, K. A.: Genetic change for clinical mastitis in Norwegian cattle - a threshold model analysis, J. Dairy Sci., 86, 369-375, 2003.

Heringstad, B., Gianola, D., Chang, Y. M., Ødegard, J., and Klemetsdal, G.: Genetic associations between clinical mastitis and somatic cell score in early first-lactation cows, J. Dairy Sci., 89, 2236-2244, 2006.

Hinrichs, D., Stamer, E., Junge, W., and Kalm, E.: Genetic analyses of mastitis data using animal threshold models \& genetic correlation with production traits, J. Dairy Sci., 88, 2260-2268, 2005.

Kadarmideen, H. N., Thompson, R., and Simm, G.: Linear and threshold model genetic parameters for disease, fertility, and milk production in dairy cattle, Anim. Sci., 71, 411-419, 2000.

Koivula, M., Mäntysaari, E. A., Negussie, E., and Serenius, T.: Genetic and phenotypic relationships among milk yield and somatic cell count before and after clinical mastitis, J. Dairy Sci., 88, 827-833, 2005.

Madsen, P. and Jensen, J.: DMU - a package for analysing multivariate mixed models, Version 6, release 5.0, Aarhus University, Foulum, Denmark, available at: http://www.dmu.agrsci.dk/ DMU/ (last access: 30 April 2015), 2010.
Negussie, E., Koivula, M., and Mäntysaari, E. A.: Genetic parameters and single versus multi-trait evaluation of udder health traits, Acta Agric. Scand. S. A-Anim. Sci., 56, 73-82, 2006.

Negussie, E., Strandén, I., and Mäntysaari, E. A.: Genetic association of clinical mastitis with test-day somatic cell score and milk yield during first lactation of Finnish Ayrshire cows, J. Dairy Sci. 91, 1189-1197, 2008.

Odegard, J., Heringstad, B., and Klemetsdal, G.: Short communication: Bivariate genetic analysis of clinical mastitis and somatic cell count in Norwegian dairy cattle, J. Dairy Sci., 87, 35153517, 2004.

Pérez-Cabal, M. A. and Charfeddine, N.: Genetic relationship between clinical mastitis and several traits of interest in Spanish Holstein dairy cattle, Interbull. Bulletin, 47, 77-81, 2013.

Pérez-Cabal, M. A., de los Campos, G., Vazquez, A. I., Gianola, D., Rosa, G. J. M., Weigel, K. A., and Alenda, R.: Genetic evaluation of susceptibility to clinical mastitis in Spanish Holstein cows, J. Dairy Sci., 92, 3472-3480, 2009.

Pritchard, T., Coffey, M., Mrode, R., and Wall, E.: Genetic parameters for production, health, fertility and longevity traits in dairy cows, Animal, 7, 34-46, 2013.

Vazquez, A. I., Gianola, D., Bates, D., Weigel, K. A., and Heringstad, B.: Assessment of Poisson, logit and linear models for genetic analysis of clinical mastitis in Norwegian Red cows, J. Dairy Sci., 92, 739-748, 2009.

Wang, X., Zhong, J., Gao, Y., Ju, Z., and Huang, J.: A SNP in intron 8 of $C D 46$ causes a novel transcript associated with mastitis in Holsteins, BMC Genomics, 15, Article 630, 2014.

Wolf, J., Wolfová, M., and Štípková, M.: A model for the genetic evaluation of number of clinical mastitis cases per lactation in Czech Holstein cows, J. Dairy Sci., 93, 1193-1204, 2010.

Wolfová, M., Štípková, M., and Wolf, J.: Incidence and economics of clinical mastitis in five Holstein herds in the Czech Republic, Prev. Vet. Med., 77, 48-64, 2006.

Wu, X. L., Heringstad, B., and Gianola, D.: Exploration of lagged relationships between mastitis and milk yield in dairy cows using a Bayesian structural equation Gaussian-threshold model, Genet. Sel. Evol., 40, 333-357, 2008.

Zwald, N. R., Weigel, K. A., Chang, Y. M., Welper, R. D., and Clay, J. S.: Genetic analysis of clinical mastitis data from on-farm management software using threshold models, J. Dairy Sci., 89, 330 336, 2006. 